\title{
O PERFIL PROFISSIONAL DO QUÍMICO FRENTE ÀS NOVAS REALIDADES DAS ORGANIZAÇÕES INDUSTRIAIS
}

\author{
Joyce Mary Adam de Paula e Silva
}

Departamento de Educação, Instituto de Biociências, UNESP Rio Claro, Av. 24A, 1515, Bela Vista, 13506-900 Rio Claro - SP

Recebido em 19/4/99; aceito em 28/9/00

\begin{abstract}
THE PROFESSIONAL PROFILE OF CHEMISTS AND THE NEW REALITY OF INDUSTRIAL ORGANIZATIONS. The objective of this paper is to reflect about the professional profile required of chemists by the chemical industry employing new management practices. This paper includes: a) historical synthesis of the appropriation of chemical knowledge by the industrial sector, b) a discussion of today's industrial organization and a comparison between the professional profile of chemists as expected by the taylorist and fordist standards of production and that expected in the context of flexibilization and globalization of production.
\end{abstract}

Keywords: professional profile; management of chemical industries; globalization and jobmarket.

O objetivo do presente trabalho é fazer uma reflexão sobre o perfil do químico de nível superior exigido pelo mercado de trabalho, à luz da visão do próprio químico sobre sua atuação nas empresas e das novas práticas gerenciais implantadas nas mesmas.

\section{ESTRUTURA TEÓRICA}

Neste trabalho serão desenvolvidos os seguintes tópicos:

- uma síntese histórica sobre a incorporação do conhecimento químico no setor industrial;

- uma síntese sobre a criação dos cursos superiores no Brasil e os cursos de química nesse contexto;

- uma análise a respeito da organização produtiva industrial nos dias de hoje, estabelecendo-se um paralelo entre o profissional esperado pelos padrões taylorista e fordista de produção e o esperado no contexto da flexibilização da produção e globalização, aspectos fundamentais para a organização produtiva atual. Dentro desse contexto será analisada a indústria brasileira e as características que predominam nela em termos da organização produtiva ;

Partindo-se do referencial descrito nos itens anteriores e dos resultados da pesquisa de campo realizada, apresenta-se uma análise a respeito do perfil profissional esperado.

\section{MÉTODOS E TÉCNICAS DE PESQUISA}

Os métodos e técnicas de pesquisa utilizados foram :

- Estudo bibliográfico com o objetivo de realizar uma síntese sobre: a incorporação do conhecimento científico pelo setor produtivo e a química nesse contexto; - o perfil profissional requisitado nas diferentes fases do desenvolvimento industrial, enfocando mais de perto o fordismo e a acumulação flexível.

- Entrevistas semi-estruturadas junto aos químicos de nível superior, que atuam em indústrias no Estado de São Paulo, com o principal objetivo de obter dados sobre a formação acadêmica recebida e a atuação profissional, isto é, as habilidades requisitadas pela empresa face às habilidades adquiridas na fomação acadêmica. As entrevistas foram chamadas de semi-estruturadas por possuirem um roteiro orientador, com as seguintes questões: a) local onde realizou o curso de graduação; b) características principais do currículo do curso de graduação realizado; c) cargo que ocupa na empresa; d) caráter da atividade que desenvolve; e) grau de liberdade de ação no trabalho; f) utilização dos conhecimentos adquiridos durante o curso de graduação no exercício profissional; g) tipo de treinamento recebido na empresa; h) forma e conteúdo do treinamento; i) contribuição do treinamento realizado para o desempenho profissional; j) visão do próprio trabalho; k) relacionamento com os colegas de trabalho e com outros níveis hierárquicos; 1) relação entre as estruturas da empresa, a satisfação no trabalho e o exercício profissional; m) lugar do trabalho na vida do profissional.

Foram selecionadas três empresas químicas, uma do ramo de tintas (multinacional Argentina), outra de química e petroquímica ( multinacional francesa) e outra de corantes e matéria prima para borracha(capital nacional). Foram entrevistados um total de 20 químicos, distribuídos de acordo com a tabela que segue:

\begin{tabular}{|c|c|c|}
\hline Empresa & $\begin{array}{c}\mathrm{n}^{\circ} \text { de Químicos } \\
\text { Entrevistados }\end{array}$ & $\begin{array}{l}\text { Função } \\
\text { Exercida }\end{array}$ \\
\hline $\begin{array}{c}\text { A } \\
\text { (Multinacional } \\
\text { Francesa) }\end{array}$ & 08 & $\begin{array}{l}\text { Líderes de Área } \\
\text { de Pesquisa (3) } \\
\text { Técnicos (4) } \\
\text { Pesquisador (1) }\end{array}$ \\
\hline $\begin{array}{c}\text { B } \\
\text { (Capital } \\
\text { Nacional) }\end{array}$ & 05 & $\begin{array}{l}\text { Chefe de } \\
\text { Laboratório (1) } \\
\text { Recursos Humanos (1) } \\
\text { Pesquisador (1) } \\
\text { Técnico (2) }\end{array}$ \\
\hline $\begin{array}{c}\text { C } \\
\text { (Multinacional } \\
\text { Argentina) }\end{array}$ & 07 & $\begin{array}{l}\text { Chefes de } \\
\text { Laboratório (3) } \\
\text { Pesquisador (1) } \\
\text { Setor Comercial (1) } \\
\text { Técnicos (2) }\end{array}$ \\
\hline
\end{tabular}

As entrevistas com os profissionais foram um dos principais pontos de análise da pesquisa na medida em que se teve como referencial teórico metodológico os sujeitos como participantes da construção das estruturas sociais, não somente como sujeitos passivos, mas também como sujeitos que resistem e reelaboram as normas estabelecidas. Dessa forma, a 
análise realizada teve como referencial não somente princípios e valores na ótica das indústrias ou dos currículos formalmente estabelecidos,mas principalmente interpretações dos químicos a partir de sua vivência profissional.

\section{CONHECIMENTO CIENTÍFICO, A QUÍMICA E O DESENVOLVIMENTO INDUSTRIAL}

A relação entre a ciência e as questões concretas da produção e do desenvolvimento econômico começa junto com o desenvolvimento do capitalismo, quando a nova classe que estava emergindo, a burguesia industrial, passou a ver a ciência como mola propulsora de seu desenvolvimento.

Antes do surgimento do capitalismo como modo de produção generalizado, isto é, até os séculos XVI e XVII na Europa o acervo do conhecimento científico fundamental no ocidente era essencialmente o da antiguidade clássica, o dos gregos antigos, como conservado pela erudição árabe e nos monastérios medievais.

A ciência, depois do trabalho,foi,segundo Braverman a última propriedade social a converter-se em auxiliar do capital A incorporação da ciência às indústrias fez com que ela passasse do domínio dos filósofos, amadores,de latoeiros e gente rica e ociosa para o domínio das organizações industriais, que começaram a financiá-la

Há autores que consideram que a incorporação da ciência à empresa capitalista começou na Alemanha, pois ao tempo em que a Inglaterra e os EEUU empregavam cientistas com grau universitário apenas esporadicamente, para ajuda em problemas específicos, a classe capitalista alemã já tinha criado laboratórios industriais, sociedades profissionais e associações comerciais nas Universidades e já procurava na pesquisa sob patrocínio governamental um esforço científico tecnológico continuado como a nova base para a indústria moderna .

Adaptando o modelo de ensino francês, a Alemanha rebatizou as escolas politécnicas com o nome de "technische Hochschulen", que cresceram independentemente do sistema universitário e que servia para formação de técnicos e engenheiros. Um dos aspectos mais marcantes dessas escolas foi sua estreita relação com os interesses industriais e comerciais, aliada à mesma tradição de pesquisa científica e teórica desenvolvida nas universidades.

O reconhecimento da importância dessa aliança com o conhecimento científico para o desenvolvimento da indústria é destacado por Mendellsohn ${ }^{2}$. Este autor cita o químico americano, Ira Remsen, que em texto de 1894 , considera que a indústria química alemã havia tido bom êxito porque desde cedo valorizou a ciência pura e o método científico. Nesse sentido, destaca que homens profundamente conhecedores da química pura eram buscados ansiosamente pelas fábricas

$\mathrm{Na}$ Inglaterra, nesse mesmo período, buscava-se o reconhecimento da importância da ciência para a sociedade, tentandose conseguir apoio material e espiritual da indústria, do governo e da própria universidade.

Homens da ciência normalmente se reuniam em associações e academias fora da universidade e uma das mais atuantes, a British Association for the Advancement of Science, criada em 1831, tinha como preocupações principais, pelo menos em seu início, a melhoria da condição dos cientistas, o avanço da ciência e o financiamento da pesquisa científica pelo governo e pelas indústrias, estabelecendo uma nova relação entre ciência, governo, indústria e universidade.

O reconhecimento da importância da ciência passava por um outro aspecto ainda : a valorização não só da ciência prática e aplicada, mas também da ciência pura, que servia de base para a outra.O químico alemão Justus Liebig, depois de uma visita à Inglaterra, observou que os trabalhos de natureza prática despertavam mais a atenção e infundiam mais respeito do que os puramente científicos, deixando transparecer um mérito maior aos primeiros.
Nos EEUU, os laboratórios de pesquisa das empresas começaram mais ou menos junto com o processo de concentração das grandes corporações industriais e da intervenção sistemática do Estado na economia. Na essência, no entanto, o envolvimento entre a ciência e a indústria ocorreu de forma diferente da alemã, devido à visão predominante, nesses laboratórios, de uma ciência mais voltada para a resolução de problemas específicos. Como expressa Braverman ${ }^{1}$ :

“ A tradição de um delgado e fácil empirismo não oferecia solo favorável para o desenvolvimento da ciência basilar e os magnatas das empresas, ainda impacientes com a pesquisa livre e não orientada, ansiosos por inovações técnicas para porcas e parafusos, não se preocupavam em ocultar, sob seu novo compromisso com a ciência, um desdém por suas formas fundamentais." (pág.146)

Tal fato perdurou até a segunda guerra mundial, quando muitos dos talentos científicos alemães, em conseqüência do nazismo, emigraram para os EEUU, imprimindo uma nova visão ao relacionamento entre a ciência e as indústrias. Um reflexo disso foi o sensível aumento do financiamento de pesquisas pelas empresas e pelo governo. Braverman ${ }^{1}$ cita que, à medida que o orçamento para pesquisa e desenvolvimento aumentou, um esquema característico de financiamento e controle apareceu; a maioria dessas pesquisas era financiada por verbas federais e controlada pela indústria privada. Assim, no início da década de 60, três quartos dessa pesquisa concentrava-se em áreas de engenharia e ciências físicas e era realizada por empresas, embora o governo federal pagasse cerca de três quintos do custo diretamente e a maior parte do restante indiretamente, mediante incentivos fiscais.

Como conseqüência do paulatino reconhecimento do valor da ciência para o desenvolvimento econômico, ela foi transformada numa mercadoria, comprada e vendida como outros implementos e trabalhos de produção. Dessa forma, como todas as mercadorias, seu fornecimento é impulsionado pela demanda, voltando-se mais às necessidades imediatas do capital. Em função desse raciocínio, Braverman ${ }^{1}$ argumenta que :

"A inovação chave não deve ser encontrada na Química, na Eletrônica, na maquinaria automática, na aeronáutica, na Física Nuclear, ou em qualquer dos produtos dessas tecnologias científicas, mas antes na transformação da própria ciência em capital”.

Assim, como a empresa industrial tem como objetivos básicos a acumulação de capital, que gera lucros para os proprietários dos meios de produção e acionistas e a produção de bens e serviços, o cálculo permanente para obter os mais baixos custos de produção é fundamental. A introdução de qualquer aperfeiçoamento técnico deve estar sujeita ao cálculo de custos e benefícios e ciência e tecnologia nessa perspectiva devem estar em função de um aprimoramento do processo de trabalho que resulte em economia de recursos e aumento dos lucros com a velocidade que o mercado exige.

Como afirma D. Harvey ${ }^{3}$, num mundo de rápidas mudanças de gostos e necessidades e de sistemas de produção flexíveis, o conhecimento da última técnica, do mais novo produto, da mais recente descoberta científica, gera a possibilidade de alcançar uma importante vantagem competitiva. Nesse quadro, o próprio saber se torna uma mercadoria a ser produzida e vendida.

A possibilidade do desenvolvimento econômico e do aprimoramento do processo de trabalho, no entanto, não se referem somente à incorporação de novas tecnologias, mas também a outros fatores, como capacidade empresarial, satisfação de objetivos e identificação dos funcionários com a organização, tornando-se o gerenciamento e o treinamento de profissionais, dentro dos princípios gerais da empresa, um dos elementos de apropriação de conhecimento.

A observação deste último fator é hoje, nas empresas, um elemento estratégico, tornando a preocupação com os "recursos 
humanos" tão importante quanto a introdução de novas tecnologias de produção ou melhoramento de produtos.

A incorporação da técnica e da ciência ao desenvolvimento econômico também veio acompanhada do desenvolvimento de técnicas de gerenciamento do trabalho, que se constituiram, com o tempo, em técnicas relacionadas à produção propriamente dita e que se relacionaram com a preparação do "novo homem", adaptado às novas exigências do setor produtivo.

No quadro da acumulação flexível, em que novas técnicas e novas formas organizacionais de produção foram instituídas, dois aspectos fundamentais se destacam. Um deles é o do acesso ao conhecimento científico e técnico, gerando uma produção organizada do conhecimento em que este toma um cunho mercadológico, segundo Tourraine ${ }^{4}$ reforçando a apropriação desses tipos de conhecimentos, enfatizando seu cunho de aplicação imediata. O outro aspecto é o da importância do controle do fluxo de informações e dos veículos de propagação do gosto e da cultura populares, promotores dos valores culturais.

\section{A INDÚSTRIA BRASILEIRA E A INDÚSTRIA QUÍMICA: ALGUMAS CONSIDERAÇÕES}

A compreensão do processo de industrialização, bem como o estágio em que se encontra a indústria brasileira e em especial a indústria química, face ao panorama mundial, é fundamental para a análise a que a presente pesquisa se propõe. Dessa forma será apresentada a seguir uma síntese de alguns estudos a respeito dessas questões, pois embora duas das indústrias pesquisadas sejam multinacionais, elas estão instaladas no Brasil há bastante tempo e têm em sua gerência profissionais brasileiros.

Duas características fundamentais do processo brasileiro de industrialização a serem destacadas são a industrialização tardia que se iniciou entre as duas grandes guerras e o modelo de substituição de importação. O período de substituição de importação teve um primeiro período centrado na produção de bens de consumo e outro, a partir da década de 50, quando a industrialização se intensificou e a importação maciça de tecnologia e a forte presença do capital internacional predominaram .Como afirma Cardoso 5 :

"O interesse governamental pelo desenvolvimento acelerado levou à escolha de um modelo de crescimento industrial que via nas inversões maciças de capitais estrangeiros nas indústrias mecânicas e pesadas o meio para transformar rapidamente o equilíbrio tradicional da economia manufatureira do Brasil, baseada nas indústrias leves e de alimentação"(pág.117).

A política de substituição de importações, ao ter por base a importação maciça de tecnologia, teve como resultado uma valorização menor da ciência e do desenvolvimento tecnológico, significando um investimento menor que $1 \%$ do PIB por ano, sendo que as empresas do setor produtivo participaram com menos de $10 \%$ desse investimento, ao longo das últimas décadas. Em países desenvolvidos esse investimento fica entre 2 e $3 \%$ do PIB, sendo que a iniciativa privada participa com 40 a $50 \%$ nos gastos nacionais nessa área, segundo dados apresentados pelo Ministro da Ciência e Tecnologia, segundo Coutinho ${ }^{6}$.

Esse autor, afirma que a partir da metade dos anos 50, com a crescente proteção do mercado nacional a importações, começaram a ser introduzidos no país os segmentos produtores de bens de consumo duráveis e de bens intermediários de maior complexidade tecnológica, cuja base técnica, em nível mundial, já se encontrava em adiantado grau de maturação. A estratégia industrial seguida para tal introdução deu-se basicamente através do investimento direto das empresas estrangeiras, principalmente no segmento de duráveis e do investimento estatal nos segmentos de maior prazo de maturação e maiores requerimentos de capital.
O processo de substituição de importações, a incorporação e a difusão de tecnologias mais modernas se deram através de constante busca de tecnologias estrangeiras por parte de um número relativamente reduzido de empresas líderes. Avolumouse a importação explícita de tecnologia e serviços tecnológicos, sem que se manifestasse, de forma sistemática, um esforço tecnológico interno paralelo ou subseqüente ao processo de compra externa de tecnologia.

Em função disso, Coutinho ${ }^{6}$ afirma que:

“ ... mesmo na última fase do ciclo de substituição de importações, a capacitação tecnológica não se colocava como requisito efetivo. $O$ esforço tecnológico interno restringia-se basicamente ao uso e ao aprendizado das práticas de produção, sendo no máximo necessária a adap-

tação de processos, matérias primas e produtos ."(p.126)

A abertura do mercado em função do contexto mundial da globalização, gerou a necessidade, em grande parte dos setores produtivos, de uma adaptação das indústrias brasileiras à nova situação. A cultura empresarial resultante de um desenvolvimento industrial voltado para a substituição de importações, com forte intervenção governamental, está tendo que se remodelar face às mudanças. Nesse quadro, a capacidade competitiva se estabelece no contexto de um ambiente competidor e próximo às regras de livre mercado .

Coutinho afirma,ainda, que as empresas multinacionais instaladas no país normalmente desenvolvem um formato organizacional derivado da matriz, apresentando uma capacidade maior de modernização e gestão. As empresas nacionais são geralmente de menor porte, apresentando formas gestionárias em que predominam o comando familiar e a gestão hierarquizada, diferentemente do que têm apresentado as indústrias multinacionais.

No entanto, segundo Coutinho ${ }^{6}$, nos anos 80 emergiu um novo formato organizacional que, em termos de produção, compatibilizou grandes escalas com a possibilidade de diferenciar e sofisticar produtos e tornou obsoletas as organizações fortemente verticalizadas e hierarquizadas, mostrando o seguinte quadro da evolução do formato organizacional das empresas competitivas:

Processos decisórios: crescente descentralização; decrescente número de níveis hierárquicos; crescente participação dos trabalhadores nas decisões e ganhos das empresas Fluxos de informação: horizontalização; crescente intensidade. Produtos: Crescente atendimento às especificações dos clientes; crescentes esforços de desenvolvimento

Processos produtivos: busca de melhoria contínua; crescente flexibilidade; baixos níveis de estoques; menores tempos mortos.

Passando-se à indústria química específicamente, temos que este é um setor relativamente novo no país, datando de mais ou menos 30 anos sua afirmação no parque industrial brasileiro, destacando-se a forte presença de empresas multinacionais, como constata Mercado Suarez ${ }^{7}$, em estudo sobre a inovação no setor de química fina.

Em termos de desenvolvimento da indústria química é importante destacar que esta indústria se baseia no conhecimento científico, tendo importância fundamental sua estrutura de pesquisa e desenvolvimento, destacando-se também a diferenciação entre os diversos segmentos da química.

Em pesquisa realizada sobre indústrias do setor de química fina de capital nacional, Mercado Suarez ${ }^{7}$ ressalta a importância das relações usuário/produtor como eixo motor de inovações, citando estudo de Freeman, que mostra que as empresas inovadoras e bem sucedidas se caracterizavam por entender e prestar atenção especial às necessidades e circunstâncias dos potenciais usuários.

Como obstáculos ao desenvolvimento de indústrias nesse setor, Mercado Suarez ${ }^{7}$ aponta três aspectos principais, que seriam a falta de qualificação de pessoal,a capacidade gerencial 
e a questão do mercado. A falta de pessoal com qualificação é apontada como o principal obstáculo ao desenvolvimento das indústrias pesquisadas por esse autor A crítica principal é quanto à inadequação da formação dos profissionais às demandas específicas dos diferentes ramos, sendo necessário, em alguns casos, que estes, para se adaptar aos requisitos da empresa, recebessem um ano ou mais de formação em serviço.

A capacidade gerencial aparece também como um dos problemas para a inovação nas indústrias brasileiras pesquisadas por esse autor, principalmente nas indústrias criadas por profissionais universitários, aparecendo como um fator tão importante quanto o aspecto tecnológico para o sucesso dessas empresas.

Essa conclusão vem ao encontro das análises gerais que discutem a questão da competitividade das indústrias no panorama econômico atual da globalização e da flexibilização de mercados.

\section{RESULTADO DAS ENTREVISTAS: PERFIL PROFISSIONAL E CULTURA ORGANIZACIONAL}

Serão apresentadas a seguir as principais análises das entrevistas realizadas. Nessas análises foram enfatizadas as percepções dos químicos a respeito da cultura organizacional e o perfil profissional requisitado pela empresa.

\section{Empresa A}

Esta empresa adotou como modelo gerencial o Gerenciamento de Qualidade Total, buscando uma mudança profunda na cultura da empresa, que alterasse todas as relações em seu interior. Na perspectiva dos profissionais entrevistados, esta empresa apresenta como princípios marcantes de sua cultura três aspectos, que seriam: descentralização de poder e maior responsabilidade do profissional com seu trabalho; necessidade de comprometimento com os princípios da empresa; maior cobrança de "participação" do profissional na empresa, expressada principalmente pela capacidade de iniciativa e criatividade.

Além desses pontos, destaca-se ainda o princípio de que o trabalhador é parte de um sistema, em que as ações são integradas. Se nas formas tradicionais de organização do trabalho as intervenções estavam centradas no trabalhador, agora é destacado o desempenho e a interação deste com o sistema.

A ideologia que perpassa tal concepção pressupõe um envolvimento do indivíduo com o sistema a ponto de pretender que este se sinta "dono do negócio", visualizando a empresa como sendo do coletivo e, portanto assumindo que os bons resultados de seu trabalho se revertem em satisfação para o próprio profissional:

"Eu percebi o ano passado que não era suficiente para mim, como um dono de negócio, digamos assim, um laboratório fornecedor de serviços, me preocupar com a questão técnica, rigor técnico adequado às exigências dos meus clientes $e$ só estar olhando a questão do gerenciamento dentro de uma visão sistêmica, ficou claro para mim que eu tinha que buscar informações na área de marketing, que eu não tinha. Desde 1984 eu era um homem industrial”.

A perspectiva de ser dono do próprio negócio dá a idéia de um afrouxamento das contradições que poderia haver entre capital e trabalho, na medida em que o profissional estaria produzindo para si próprio sendo, portanto, responsável pela qualidade e resultado de seu próprio trabalho e, de certa forma, dono dos lucros também.

Ser o "dono do negócio" também implicaria uma maior liberdade de criação e descentralização do poder, além de um maior compromisso com os resultados do trabalho, originando, a partir daí, maior obrigação de estar propondo formas de melhorias do trabalho e da organização como um todo.

Os princípios organizacionais dessa empresa se refletem na visão dos químicos sobre seu perfil profissional, no sentido de que se consideram como profissionais que precisam ter não só habilidades técnicas, mas também habilidades gerenciais .

Além da habilidade técnica específica, em função dos princípios de uma nova orientação gerencial que a empresa A tem implantado, o perfil do químico deveria incorporar outras habilidades. Pode ser destacado de início que não é suficiente o profissional ter o conhecimento de uma técnica e aplicá-la. É necessário que avalie constantemente as possibilidades de aperfeiçoamento da mesma. Como afirma um dos químicos:

"O técnico de bancada antes do projeto de excelência só fazia análise, agora ele também tem a função de elaborar os métodos, pensar sobre eles."

A função gerencial exercida pelos químicos, pode ser ilustrada pelas duas falas que serão reproduzidas a seguir:

"Eu exerço um papel de referência analítico, quer dizer, o know how está comigo. Eu faço $60 \%$ de aconselhamento técnico e os outros 30, 40\% é gerencial administrativo".

"Cada célula tem um líder, mas todos tem um trabalho, ele entra em contato com o cliente, reúne as equipes, faz uma discussão com as equipes, dá as direções, funciona como uma espécie de consultoria. O cliente tem suas preferências, ou ele liga para mim ou liga para um comandado da minha equipe. Hoje eu sou um pouco de bancada, $50 \%$ de administração e $50 \%$ de discussão teórica."

O perfil do profissional buscado pela empresa é resumido pela fala de um dos profissionais, que será reproduzida a seguir:

"A gente estabelece o perfil: pessoas que sabem se comunicar, tenham bons conhecimentos técnicos e hoje a gente procura vendedores também, porque nós somos prestadores de serviço, então as pessoas têm que comprar serviço."

\section{Empresa B}

Nesta empresa o modelo gerencial predominante é o da administração familiar pelo fato de que o proprietário da empresa gerencia diretamente os rumos da produção e cuida para que a sucessão seja feita dentro da família.

Foi iniciado um programa de treinamento baseado no $\mathrm{Ge}-$ renciamento de Qualidade Total, mas foi interrompido por problemas ocorridos dentro da empresa.

A percepção dos químicos, sobre a cultura organizacional dessa empresa, orienta-se no sentido de que há uma explícita centralização das decisões nas mãos do proprietário, ficando pouco espaço de iniciativa e criatividade para técnicos e especialistas, para diversificação e introdução de inovações, sejam elas de caráter gestionário ou tecnológico. Tais aspectos confirmam as observações de Cardoso 5 sobre as "empresas clânicas".

$\mathrm{O}$ perfil profissional delineado pelos químicos da empresa B refere-se à demanda por profissionais com boa base técnica e capacidade de improvisação, devido ao baixo investimento tecnológico característico dessa empresa. Criatividade nessa empresa relaciona-se à capacidade de adaptação de processos previamente elaborados às condições concretas que a empresa oferece. As falas reproduzidas abaixo ilustram essas observações:

"Meu trabalho é tentar sintetizar no laboratório os produtos das patentes e dos artigos para serem desenvolvidos"

"Meu trabalho é a nível de laboratório, depois é levado para a fábrica, para a produção. Desenvolvo as experiências levando em conta já as condições que vão ser encontradas na fábrica. Então você tem que usar bastante criatividade. Na indústria nacional você precisa bastante criatividade. Você não tem todos os equipamentos necessários, você tem que improvisar, tem que ser criativo."

Ao contrário da Empresa A, onde o profissional se especializa em determinadas áreas, na Empresa $\mathrm{B}$, os profissionais circulam pelos diferentes setores, como pode ser observado pela fala reproduzida a seguir: 
"Aqui a gente aprende muito, porque você é obrigado a fazer tudo, você é obrigado a criar, pesquisar, você tem que procurar".

Outro aspecto marcante, que diferencia esta das outras duas empresas pesquisadas refere-se ao tipo de responsabilidade com o trabalho. Devido aos modelos gerenciais adotados pelas outras duas empresas, existe o pressuposto de que não existe a separação entre execução e planejamento, isto é, quem executa, a princípio deve também planejar. $\mathrm{Na}$ empresa $\mathrm{B}$, no entanto, observou-se uma certa separação entre execução e planejamento do trabalho, nos moldes do Taylorismo, como pode ser visto pela seguinte fala:

"Meu trabalho específico não exige que eu elabore processos e análise, são outras pessoas que fazem isso, a gente pode contribuir e ajudar".

\section{Empresa C}

A empresa C, como conseqüência das reformulações gerenciais, passou por três momentos diferentes em sua cultura organizacional. Saiu de uma estrutura familiar, no início da década de 80, para uma estrutura mais profissional em 1996, que, segundo os químicos entrevistados, privilegiou mais a área comercial em detrimento da área técnica. Essa segunda reformulação introduziu novas concepções, baseadas em alguns preceitos do Gerenciamento da Qualidade Total, sem no entanto abraçar esse modelo como único. O terceiro momento foi uma relativização do modelo gerencial em vigor em conseqüência das resistências encontradas junto aos funcionários. Um exemplo dessa resistência pode ser vizualizada pela seguinte fala, de um dos químicos entrevistados:

"Essa mudança de cultura que começou em 86-87 não mudou nada, foi um projeto político, traumático, de consequências ruins. A atividade técnica, que eu acho que numa empresa de tintas é o celeiro, que é o lugar que pensa, foi quase dizimada... O pessoal que tinha capacidade técnica saiu para a área comercial, procurando status e maior valorização."

Concluiu-se, a partir dos discursos dos profissionais entrevistados, que os mesmos acreditam que a área técnica deveria ter um espaço maior na definição da estruturação da empresa como um todo, pois como indústria química essa área seria o centro de criação. Esses profissionais consideraram que a excessiva valorização do mercado aborta a capacidade de iniciativa e criação que poderiam surgir nos laboratórios.

Quanto à percepção de seu trabalho, os químicos entrevistados apresentaram uma visão de que este tenha um perfil de investigação e pesquisa, em termos de um espaço de criação de conhecimento, mesmo que seja um conhecimento técnico específico, do ramo de tintas. Como afirma um deles:

"Meu trabalho é um trabalho muito mais de pesquisa, porque eu tenho que estar sempre atento ao que o mercado quer e o conhecimento que eu tenho para aproveitar. Tem que estar sempre atento às novidades."

A perspectiva de criatividade necessária ao trabalho realizado também está presente nas falas dos químicos entrevistados. Esta criatividade porém estaria limitada pelas determinações do mercado, como pode ser observado pelas seguintes observações de dois deles:

"Hoje já existe um entendimento no sentido de que se vamos pensar em algum produto novo, não é só copiar, temos que inovar. O que é que a gente tem para oferecer de novo, quais são as aspirações do mercado, não o que já existe, mas o que o mercado gostaria de ter, aí a gente soma com o que a gente conhece."

"Se tem poucos trabalhos de pesquisa, a maior parte é realizada nas empresas e são guardadas, então, de repente você vê uma característica nova, você tem que procurar desenvolver e vai muito da criatividade, você tem chance de fazer muita coisa. Exige que você se envolva, se bem que o pulo do gato você não encontra em livros, você tem que fazer, tem que buscar, tem que utilizar sua imaginação."

\section{CONCLUSÕES}

\section{Perfil Profissional do Químico no Contexto da Flexibilidade e da Globalização}

Nas reflexões apresentadas,destacou-se o caráter mercadológico assumido pelo conhecimento científico e tecnológico, no sentido de que deixa seu lado exploratório e de explicação do mundo, e seu lado ornamental, assumindo paulatinamente, a partir da revolução industrial, um caráter cada vez mais utilitário e econômico.

As formas de gestão do trabalho e as teorias administrativas e organizacionais vêm confluir, passando do estudo da melhor forma de realizar as tarefas para a preocupação com o controle dos veículos de propagação e criação dos valores culturais.

Nesse quadro, o perfil de homem buscado nas diferentes etapas de apropriação do conhecimento adquire caráter distinto. Com o taylorismo a atenção estava voltada somente para as tarefas e a adequação do homem a estas. Com o fordismo, além das tarefas rotineiras e parcelarizadas controladas no âmbito da produção, a racionalização do trabalho busca um homem moldado não somente de acordo com os padrões técnicos da organização industrial mas também com os valores morais . A seguinte citação de $\mathrm{Harvey}^{8}$ ilustra bem esta afirmação:

"Em 1916, Ford enviou um exército de assistentes sociais aos lares dos seus trabalhadores 'privilegiados'(em larga medida imigrantes) para ter certeza de que 'o novo homem' da produção de massa tinha o tipo certo de probidade moral, de vida familiar e de capacidade de consumo prudente (isto é, não alcoólico) e 'racional' para corresponder às necessidades e expectativas da corporação."

$\mathrm{O}$ perfil humano e profissional se reestrutura na medida em que os padrões produtivos e gestionários vão sendo redefinidos.

Assim também, com a crescente adoção do modelo de acumulação flexível nas empresas, e de políticas econômicas e sociais de orientação neoliberalista, o perfil profissional exigido pelo mercado apresenta a necessidade de requisitos que diferem em alguns aspectos dos anteriores.

A redução de níveis hierárquicos e a exigência de um maior envolvimento e participação do trabalhador na elaboração de seu trabalho, assim como a importância assumida pelo mercado na definição de políticas sociais e econômicas, são elementos definidores desses requisitos.

Nesse quadro, a exigência é por trabalhadores instruídos e capazes de reelaborar suas tarefas, capazes de tomar iniciativas, não só aceitando mas desejando mudanças, assumindo o trabalho e o produto deste como propriedade sua, numa estrutura coletiva e cooperativa. O trabalhador deve observar também o princípio de que a etapa seguinte de produção, o setor para o qual é prestado o serviço, e o companheiro de trabalho são clientes que devem ser levados em conta no processo.

A busca da legitimação da estrutura social e econômica no mercado vem ao encontro de teorias gerenciais que têm no conceito de "cliente" um de seus principais fundamentos.

A criatividade, expressão que a princípio acompanha a atuação de profissionais de nível superior, visto que estes normalmente assumem posições de liderança no processo produtivo, assume características peculiares nesse contexto. Como afirma Furtado9:

"Ao consumidor cabe um papel essencialmente passivo: a sua racionalidade consiste exatamente em responder 'corretamente' a cada estímulo a que é submetido. As inovações apontam para um nível mais alto de gastos, que é a marca 
distintiva do consumidor privilegiado. Mas o padrão inicialmente restrito terá de ser superado e difundido, a fim de que o mercado cresça em todas as dimensões. As leis desse crescimento condicionam a criatividade.”( $p$. 84)

Touraine $^{4}$ afirma que a palavra consumo esteve por muito tempo dissociada da palavra produção; a sociedade de produção não combinava com a sociedade de consumo, no entanto as teorias gestionárias que colocam o cliente como o foco principal de atenção partem do princípio de que produção e consumo se encontram associados. O colega de trabalho é um cliente em potencial, a outra equipe de produção é um cliente, o estudante é um cliente e assim por diante. O conhecimento científico e tecnológico, por sua vez, adquire nessa perspectiva um caráter mercadológico que o coloca em função das demandas do mercado.

A aplicação do conhecimento científico e tecnológico por profissionais de nível superior, através de sua atuação nas organizações industriais, é delimitada pelas condicionantes sociais e econômicas, definindo uma mudança no perfil desses profissionais no sentido de se adequarem às estruturas e formas de organização da produção e gestão.

Como já foi visto anteriormente, a indústria química tem sua origem estreitamente ligada à pesquisa e aos laboratórios acadêmicos. Dessa forma, o trabalho do químico tradicionalmente relaciona-se a um envolvimento maior com a investigação científica, não só na formação universitária, mas também no que se refere ao exercício profissional. A prática, no entanto, relativiza esse conceito de pesquisa, de acordo com as condicionantes da produção industrial e do momento histórico.

Os resultados das entrevistas nas três empresas pesquisadas demonstraram algumas diferenças concernentes ao perfil profissional traçado pelos químicos, que estiveram muito em função dos princípios que orientam essas empresas. Esses princípios se relacionam aos modelos gestionários adotados e ao grau em que estes promoveram inovações que as aproximaram dos padrões empresariais internacionais, da flexibilização e da globalização.

A globalização sugere a idéia de "comunidade mundial", "mundo sem fronteiras", onde "Em todos os lugares, tudo cada vez mais se parece com tudo o mais, à medida que a estrutura de preferências do mundo é pressionada para um ponto comum homogeneizado", como afirma Levitt, citado por Ianni ${ }^{10}$. Portanto, a busca por uma identificação das indústrias com os moldes da "fábrica global" induz cada vez a inovações que as coloquem nessa comunidade mundial e as mantenham competitivas.

A globalização e o avanço tecnológico, no entanto, não significam a superação das desigualdades sociais, econômicas, políticas e culturais, assim como da dependência econômica e ideológica. Aspectos, como o reservatório de mão de obra barata dos países em desenvolvimento e o desenvolvimento das técnicas de transporte e comunicação, possibilitam que a produção ocorra em qualquer lugar do planeta, voltado para um mercado mundialmente determinado e, como afirma Kurz, citado por Ianni $^{11}$, onde o indivíduo se revela adjetivo, subalterno:

"A razão universal supostamente absoluta rebaixou-se à mera racionalidade funcional, a serviço do processo de valorização do dinheiro, que não tem sujeito, até a capitulação incondicional das chamadas 'ciências do espírito'. $O$ universalismo abstrato da razão ocidental revelou-se como mero reflexo da abstração real objetiva do dinheiro".(p. 20)

As teorias gestionárias, no contexto da globalização e da acumulação flexível, mascaram esses aspectos na medida em que procuram estabelecer nos indivíduos o sentimento de que aqueles que "vestirem a camisa" e acreditarem nesses princípios serão aceitos em igualdade de condições junto aos mais desenvolvidos e ricos. Para tanto passam a ilusão de que "não é o lucro" o princípio fundamental das novas culturas a serem criadas nas organizações industriais, mas sim a "qualidade", só que este é um requisito fundamental de competitividade.

As questões aqui abordadas, referentes aos princípios da acumulação flexível e às teorias gestionárias, foram referenciais de análise utilizados na percepção do perfil profissional do químico, porque as empresas que atuam no Brasil também têm realizado esforços para se colocar num mercado globalizado, como forma de sobrevivência, sendo que esses esforços tem se diferenciado de acordo com as diretrizes tomadas, refletindose na definição do perfil profissional requisitado.

Alguns elementos definidores do perfil do profissional delineado pelos químicos e pelos princípios orientadores das empresas, face às reflexões apresentadas, foram :a) o caráter do trabalho e o sentido da criatividade; b)o grau de envolvimento e independência ou incorporação dos valores e princípios orientadores da produção;c) as novas habilidades requeridas nesse contexto

O caráter do trabalho e o sentido da criatividade delineados pelos profissionais face às inovações ou manutenção das teorias gestionárias reforçaram a compreensão de que, fundamentalmente, seu trabalho possui uma característica de investigação e pesquisa, mas com uma diferenciação clara entre o conceito de investigação realizada na universidade e na indústria.

A criatividade na pesquisa que é realizada na indústria apresentou-se na direção das reflexões realizadas anteriormente, em que a pesquisa deixa de ser um "exercício livre do espírito" para voltar-se para as demandas do mercado,principalmente nas empresas em que foram implantadas inovações gestionárias e onde o investimento tecnológico é alto. $\mathrm{Na}$ empresa de administração familiar, a criatividade ficou delimitada pelas diretrizes elaboradas pelo proprietário da empresa e se apresentou mais com um caráter de improvisação e adaptação de processos já desenvolvidos, do que como um processo de criação.

A possibilidade de criação dentro das organizações industriais esteve, desde o início da incorporação da ciência e da tecnologia aos processos industriais, limitada pelas condicionantes desse modelo de acumulação. No contexto da globalização e do neoliberalismo, em que os olhares estão voltados para o mercado, a possiblidade de criação se restringe ainda mais, na medida em que os que teriam o papel de criar assumem a posição de consumidores, cuja racionalidade consiste em responder unicamente aos estímulos desse mercado.

Essa questão vincula-se imediatamente ao grau de independência com que os químicos se posicionaram frente às diretrizes organizacionais das empresas em estudo.

As percepções a respeito da cultura da empresa e do perfil profissional demonstraram que, embora os princípios gerenciais das três empresas tenham sido definidos em bases teóricas semelhantes, principalmente o gerenciamento da qualidade total, foram implantados de formas diferentes e assimilados também de modos diversos pelos químicos.

$\mathrm{Na}$ empresa A foi observada uma sintonia com os princípios do modelo gerencial implantado, observando-se certo entusiasmo por essas diretrizes, principalmente em relação à quebra das estruturas hierárquicas rígidas e à possibilidade de o profissional participar mais nas definições de seu trabalho. Este último princípio se expressa de forma bastante significativa na expressão "dono do negócio", utilizada por alguns químicos ao se referirem ao seu trabalho.

O discurso que identifica o profissional como o "dono do negócio", isto é, que dá ao profissional a sensação de que é ele que tem o domínio de determinado setor ou técnica, configura-se numa forma de comprometimento e responsabilidade que transfere o controle do trabalho, que antes era exercido por um "chefe" ou supervisor, para o nível da consciência individual de cada um. É por esse motivo que ocorre a substituição do cargo de chefia pelo cargo de liderança, simbolizando mais um articulador do que um supervisor, pois a supervisão é feita por cada membro da organização sobre si mesmo e sobre os outros. 
O principal ponto de diferenciação entre a empresa A e a empresa $\mathrm{C}$ caracterizou-se pela resistência dos químicos desta última empresa ao atrelamento da área técnica à área comercial. Notou-se uma indignação muito grande por parte de alguns químicos quando estes se referiram às reformulações que deram à área comercial um destaque e um peso maior nas decisões das diretrizes da produção .

Para os químicos que visualizam o seu exercício profissional num âmbito que preserve algumas características de investigação e pesquisa, a supremacia do mercado, princípio que orientou as reformulações citadas, retiraria da "área técnica", forma como eles se referem à sua área, a possibilidade de qualquer criação, na medida em que somente o mercado definiria as diretrizes de seu trabalho, o que, em termos estratégicos, eles consideram inviável para a sustentação de uma produção, como eles mesmos afirmam:"Logicamente que o que está no mercado é algo que já foi digerido muito antes no laboratório. Eles não percebem que tem muitos anos anteriores ao produto ser lançado no mercado".

A consciência das limitações do atrelamento ao mercado, que esses químicos apresentam, tem um significado muito importante na compreensão de que a ilusão da globalização e da quebra das barreiras, como já foi afirmado anteriormente, por si não supera a relação de dependência econômica, na medida em que a reprodução do mercado não permite o avanço científico e tecnológico e que não há criação.

Os químicos da empresa B não apresentaram grandes conflitos e nem entusiasmo como os das empresas anteriores, mantendo-se, no entanto, numa determinada posição de espera, pois têm certa consciência de que tanto a infra-estrutura tecnológica, quanto o modelo de gestão familiar que predomina se devem às características de monopólio que a empresa mantém no país.

No panorama da globalização, no entanto, as estruturas produtiva e administrativa da empresa $B$ podem não apresentar a competitividade no mesmo nível das empresas que estão se adequando a essa nova realidade pois, nesse quadro, a manutenção dos monopólios fica mais difícil devido à ampliação das ofertas de produtos e porque a diversificação do mercado exige estruturas mais ágeis.

As habilidades requeridas pelo mercado de trabalho, definidoras do perfil profissional delineado, apresentaram-se diferenciadas entre as empresas que introduziram inovações gerenciais e a que se manteve no modelo de gestão familiar.Nas primeiras, as habilidades relacionadas à capacidade de gerência de mercados e de negócios apareceram aliadas às habilidades do conhecimento técnico específico

O ponto comum nos discursos dos químicos foi o caráter de investigação e pesquisa que marca a função deles e o ponto divergente ficou por conta da importância ou não da incorporação de habilidades gestionárias e econômicas na sua formação, em função das exigências do mercado de trabalho.

$\mathrm{Na}$ empresa A, onde estão melhor definidos e assimilados os princípios gestionários implantados, os profissionais entrevistados apresentaram uma visão bastante afinada com os princípios da empresa, mostrando o outro lado de sua função técnica, que exige deles um conhecimento mais abrangente em termos de compreender sua atividade na dimensão econômica.

$\mathrm{Na}$ empresa $\mathrm{B}$, o requisito de um profissional que possua um perfil que alie uma formação com conhecimentos voltados para a gestão de negócios, além dos técnicos, ainda não é marcante, na medida em que a primeira função não é atribuição do químico, mas sim do proprietário da empresa.

$\mathrm{Na}$ empresa $\mathrm{C}$, a resistência da área técnica em aceitar a supremacia da área comercial na definição dos rumos de seu trabalho configurou-se numa percepção de que o trabalho do químico nessa empresa estaria mais relacionado a um trabalho de investigação e à dinâmica de um desenvolvimento tecnológico do que a uma dinâmica do mercado. O perfil profissional delineado então tendeu para uma valorização da formação técnica e do espírito investigativo da função do químico, cuja atuação não seria determinada somente pelas condicionantes do mercado.

As habilidades referentes ao conhecimento técnico merecem algumas considerações devido à diferenciação estabelecida entre especialização e atuação polivalente do químico nessas empresas. Nas empresas que estão se adequando ao contexto da globalização, que estão promovendo inovações gerenciais e tecnológicas, como é o caso das empresas A e C, os químicos desenvolvem um aprofundamento ou são contratados porque já possuem uma especialização em determinadas áreas estratégicas, ao contrário da empresa $\mathrm{B}$, onde o químico transita pelas diferentes especialidades da química, sem se aprofundar e se especializar em uma técnica específica.

O conhecimento base para as especializações, no caso da empresa A, é adquirido na própria empresa, principalmente em unidades da matriz e tem uma forte ligação com a proposta gerencial implantada por esta empresa, que parte da descentralização administrativa, gerando lideranças em setores específicos, que ficam como os "donos do negócio" e assumem um compromisso maior com a empresa.

A "polivalência" da atuação do químico da empresa B explicar-se-ia pela administração centralizada, cabendo a esses químicos ter um conhecimento suficientemente genérico para fazer as adaptações necessárias aos processos a serem desenvolvidos.

A referência à formação recebida no curso de graduação teve como ponto comum a observação de que há um distanciamento entre o que é trabalhado na Universidade e o que é realizado concretamente no exercício profissional. Este fato merece algumas considerações a respeito, não somente da distinção de natureza das organizações, como também da relativização de uma vinculação estreita, direta e imediata entre formação acadêmica e mercado de trabalho.

Esse distanciamento a que se referiram os entrevistados pode ser atribuído a alguns fatores dentre os quais destacam-se:

a) A resistência da comunidade universitária a uma aproximação maior com a indústria, que estaria relacionada ao receio da perda de identidade da instituição universitária e de um atrelamento desta aos padrões da indústria, com a conseqüente perda do referencial crítico.

b) A estrutura burocrática da instituição universitária, que dificulta o acompanhamento da diversificação e agilidade da produção industrial e do mercado.

c) A compreensão das indústrias de que a instituição universitária teria que se orientar pelo mercado, modelando-se de acordo com as exigências dos padrões industriais em vez de constituir-se num espaço de reflexão alternativa das questões sociais, pensando os problemas concretos da produção, e o desenvolvimento social,independentemente da lógica do mercado.

Na possibilidade de uma aproximação e cooperação entre duas organizações é necessário que haja uma compreensão da natureza que caracteriza cada uma das organizações, para que essa cooperação se dê em nível de igualdade e de forma crítica, não simplesmente integradora.

Dessa forma, tanto as pesquisas realizadas na universidade, como a formação propiciada por esta não têm que estar totalmente voltadas para os interesses da indústria, pois dessa forma os interesses da primeira estariam sendo subjugados pela última, configurando-se numa relação de desigualdade no que se refere à autonomia dessas diferentes organizações.

A universidade moderna, que surge com a preocupação da incorporação da investigação científica, básica ou aplicada, é guardiã e reprodutora de um saber que serve de base para a produção do saber interessado. Para manter essa característica, como os próprios profissionais expressaram, essa organização precisa de tempos e referenciais diferentes dos determinados 
para a organização industrial .

A indústria, por sua vez, tem no lucro sua principal motivação, mesmo que os meios para atingir tal objetivo passem por formas mais humanizadas, mais interessantes e criativas. $\mathrm{O}$ modelo de acumulação, como já foi afirmado anteriormente, mesmo na flexibilização e na globalização, continua sendo o capitalista, e a referência ao mercado como elemento regulador, tanto de relações econômicas como sociais, restringe ainda mais a perspectiva da criação como um exercício superior do espírito .

Dessa forma, pode-se concluir que a formação acadêmica deve abranger os elementos necessários para habilitar o profissional no âmbito da técnica, da política e da gestão empresarial, incorporando as novas tendências da organização do trabalho nas indústrias, mas precisa manter resguardado o espaço de livre criação, que caracteriza a organização universitária.

\section{LEITURAS ADICIONAIS SOBRE O TEMA}

Antunes, R.; Adeus ao Trabalho? Ensaio Sobre as Metamorfoses e a Centralidade do Mundo do Trabalho.Cortez, $3^{\mathrm{a}}$ ed.; Campinas, 1995.

Bernal, J.D.;História Social de La Ciência. Edições Península; Barcelona, 1976.

Drucker, P. As Novas Realidades. Pioneira; São Paulo, 1989 .

Gordon, R. Les Entrepreneurs, L'Entreprise et Les Fondements Sociaux de L'Inovation. In Sociologie du Travail,no.1,1989.

Hennock, E. P. "Technological Education in England, 1850-1926: The Uses of a German Model". In History of Education, vol 19.
Humphrey, J. ;” O Impacto das Técnicas 'Japonesas' de Administração na Indústria Brasileira". In Novos Estudos, CEBRAP, no38, março, 1994.

Nelkin, D.; Nelson,R. Commentary: University-Industries Alliances. In Science, Technology \& Human Values, vol.12, 1987.

Thèvenet, M.;A Cultura de Empresa Hoje em dia. In Revista de Administração,no. 2; abr.jun/1991.

\section{REFERÊNCIAS}

1. Braverman, H.; Trabalho e Capital Monopolista. Guanabara, $3^{\mathrm{a}}$ ed.; R.J.,1987; p.146.

2. Mendellsohn, E.; La Emergência de la Ciência como Profesión en el siglo decinueve europeo.In Hill,K. The Management of Scientists. Beacon Press; Boston,1964.

3. Harvey, D.; Condição Pós-Moderna.Ed. Loyola, $4^{2}$ ed.;São Paulo, 1994; p.122.

4. Touraine, A.; Crítica da Modernidade. Ed. Vozes; Rio de Janeiro, 1994; p. 153.

5. Cardoso, F. H.; Empresário Industrial e Desenvolvimento Econômico no Brasil. Difusão Européia do livro, $2^{\mathrm{a}} \mathrm{ed}$., S.P., 1972; p.117.

6. Coutinho, L.; Estudo da Competitividade da Indústria Brasileira .Papirus,Campinas, 1994; p. 126.

7. Mercado Suarez, A.; Dissertação de Mestrado; Instituto de Geociências - Unicamp, Campinas, 1992; p.13.

8. Harvey, D.; Op. Cit.; p. 120.

9. Furtado, C.; Criatividade e Dependência na Civilização. Paz e Terra; Rio de Janeiro, 1978; p. 84.

10. Ianni, O.; Teorias da Globalização. Civilização Brasileira; Rio de Janeiro,1995; p.17.

11. Ibid.; p. 20 